\title{
Letters
}

All letters are subject to editing and may be shortened. General letters can be sent to bjgpdisciarcgp.org.uk (please include your postal address for publication), and letters responding directly to BJGParticles can be submitted online via eLetters. We regret we cannot notify authors regarding publication.

For submission instructions visit: bjgp.org/letters

\section{Are we complicit in vaccine nationalism?}

As clinicians, we are bound by a set of ethical principles that compel us to deliver limited resources according to clinical need. Not according to whether we like the patient, how rich they are, where they live, or the colour of their skin.

Allocating jabs according to clinical need has been relatively uncontentious in the UK, and we have now covered the majority of the high-risk population. Over the next few months GP surgeries will be invited to vaccinate the final risk group: healthy adults under 50 years.

There are limited global stocks of vaccine for 2021. While we jab healthy 25-yearolds (with a 1/500 000 risk of death), ${ }^{1}$ many countries will not receive enough doses to cover even $1 \%$ of their populations. ${ }^{2}$

Before we start vaccinating young and healthy Brits, we need to pause to ask how far our duty of care extends.

In posing this question I'm very aware that I have already received two doses, and therefore I do not personally bear the full risks of slowing the vaccination campaign. And I still feel mixed about the right course of action. But before rolling out the final phase we - as a primary care community - need to pause and consider if we are enabling, endorsing, and co-perpetrating a form of pernicious 'me-first' nationalism that condemns vulnerable populations to avoidable death.

\section{Luke N Allen,}

Salaried GP, Oxford; Clinical Research Fellow, London School of Hygiene \& Tropical Medicine; Director, Healthier Systems. Email: drlukeallendagmail.com

\section{Competing interests}

I have received two doses so I would not personally experience the same degree of increased risk as my non-vaccinated peers should the UK slow or postpone vaccination of healthy younger adults. I consult for the World Health Organization and have previously called on the UK Government to send vaccine doses overseas through letters in the Financial Times and BMJ, in my role as Director of Healthier Systems Ltd.

\section{REFERENCES}

1. University of Oxford. QCovid risk calculator. 2021. https://qcovid.org laccessed 16 Apr 2021).

2. Our World in Data. Coronavirus (COVID-19) vaccinations. https://ourworldindata.org/covidvaccinations (accessed 16 Apr 2021).

DOI: https://doi.org/10.3399/bjgp21X715649

\section{Alert for Lyme disease}

With the spring and summer coming there will be more people going outdoors where they may brush against vegetation and catch Lyme disease from a tick. The ticks will be on the hunt for animal blood, especially after this wet winter. Lyme disease is seen throughout the UK and is more prevalent than many people realise.' A study of GP data showed that Lyme disease is diagnosed in every region in the country. Birds can carry infected ticks, so infected ticks can be found everywhere.

For patients presenting with the erythema migrans rash, the National Institute for Health and Care Excellence (NICE) recommends diagnosis and treatment of Lyme disease without laboratory testing. ${ }^{2}$ However. more than half of all cases do not have this distinctive rash and so they need to be diagnosed using other criteria. Along with many cases not having the rash is the added difficulty that laboratory testing for Lyme disease has inherent limitations, and false negative results can occur. If the test is done too early the person may not have developed antibodies to the bacteria that causes Lyme disease.

NICE has written that, if Lyme disease is still suspected in people with a negative result who were tested within 4 weeks from symptom onset, then the test should be repeated 4-6 weeks after the first test. Lyme disease can lead to a wide range of symptoms, so diagnosis can be difficult.

Oral antibiotic treatment may be appropriate in the early stages even if there is some uncertainty about the diagnosis because avoiding a delay in treatment is important to prevent long-term morbidity. NICE recommends considering starting treatment with antibiotics while waiting for the test results if there is a high clinical suspicion of Lyme disease.
Victoria E Cairns,

Consultant Statistician

Email: v.cairns@doutlook.com

\section{REFERENCES}

1. Cairns V. Lyme disease: implications for general practice. Br J Gen Pract 2020; DOI: https://doi. org/10.3399/bjgp20X708341

2. National Institute for Health and Care Excellence. Lyme disease. NG95. 2018. https://uww.nice.org.uk/ guidance/ng95 laccessed 16 Apr 2021).

\section{Was enough, and is enough, being done to protect the primary care workforce from COVID-19?}

Kendrick et al discuss the missed opportunities to protect the primary care workforce from exposure to SARS-CoV-2, such as: personal protective equipment (PPE) shortages; Public Health England (PHE) following World Health Organization interim guidance, which advocated that healthcare workers (HCWs) use fluid-resistant surgical masks (FRSM); and filtering facepiece respirators (FFP) being restricted to HCWs performing aerosol-generating procedures (AGPs). Royal College of General Practitioners (RCGP) guidance issued in March 2020 reflects the PHE position and states, droplet and faecal spread seem to be the primary forms of transmission of coronaviruses and that it is not anticipated that FFPs will be needed in most general practice situations.? However, FRSM only protect against splashes or large droplets of body fluids; unlike FFP. they do not prevent inhalation of aerosols. ${ }^{3}$ Kendrick and others note current evidence that, like other respiratory viruses, SARSCoV-2 is transmitted by aerosols 1,4 and over distances exceeding $2 \mathrm{~m}$; the SARS-CoV-2 therein remaining infectious for hours. ${ }^{3}$

An editorial published in an occupational medicine journal supports the view that: 1) underestimating the risk of aerosol 
transmission; and 2) inadequate supplies of FFPs left many HCWs inadequately protected against inhaling aerosols containing SARSCoV-2. ${ }^{3}$ Reviewed studies demonstrated that: 1) hospital patients, visitors, and HCWs were at increased risk of infection; 2) seropositivity was higher among staff working in supposedly low-risk areas; and 3) HCWs who perform AGPs or work in ICUs were protected, with lower prevalence of infections being attributed to better air exchange rates and provision of FFPs. ${ }^{3}$ This evidence together with higher infectivity around the time of symptom onset and the emergence of readily transmitted variants warrant that RCGP guidance should be reviewed and updated as a matter of priority. Practices should review their risk assessments and controls for managing airborne exposures. Practices must also consider personal susceptibility ${ }^{5}$ and ensure that individual HCW clinical vulnerability (personal risk factors such as age, ethnicity, sex, health, and immune status) is assessed so that each HCW is provided with the correct PPE that recognises both workplace and personal risks.
Paul J Nicholson,

Occupational Physician, London.

Email: pjnicholsonadoctors.org.uk

\section{Competing interests}

Paul J Nicholson is co-author of the editorial cited as reference 3 .

\section{REFERENCES}

1. Kendrick D, Agius RM, Robertson JFR, et al. Was enough, and is enough, being done to protect the primary care workforce from COVID-19? $\mathrm{Br}$ J Gen Pract 2021; DOI: https://doi.org/10.3399/ bjgp21X714953.

2. Royal College of General Practitioners. COVID19 - GP guide personal protective equipment. 2020. https://www.rcgp.org.uk/about-us/rcgp-blog/ covid-19-gp-guide-personal-protective-equipment laccessed 16 Apr 2021).

3. Nicholson PJ, Sen D. Healthcare workers and protection against inhalable SARS-CoV-2 aerosols. Occup Med (Lond) 2021; DOI: 10.1093/occmed/ kqab033.

4. Khunti K, Adisesh A, Burton C, et al. The efficacy of PPE for COVID-19-type respiratory illnesses in primary and community care staff. Br J Gen Pract
2020; DOI: https://doi.org/10.3399/bjgp20X710969.

5. Majeed A, Molokhia M, Pankhania B, Asanati K Protecting the health of doctors during the COVID19 pandemic. Br J Gen Pract 2020; DOl: https://doi. org/10.3399/bjgp20X709925.

DOI: https://doi.org/10.3399/bjgp21X715673

\section{Yonder: antidepressant withdrawal}

It is disappointing that, in an issue of the $B J G P$ devoted to mental health, the only mention of the increasingly recognised problem of antidepressant dependence is in reference to an article published elsewhere.'

I have been in practice long enough to recall the Defeat Depression campaign of the 1990s. I recently came across some of the material distributed to GPs in support of this campaign, ${ }^{2}$ which was supported by both the Royal College of Psychiatrists (RCPsych) and the Royal College of General Practitioners (RCGP), as well as the pharmaceutical 